\title{
The Relationship between Slow Photoresponse Recovery Rate and Temporal Resolution of Vision
}

\author{
Yumiko Umino, ${ }^{1 \star}$ Rolf Herrmann, ${ }^{2 \star}$ Ching-Kang Chen, ${ }^{3}$ Robert B. Barlow, ${ }^{1 \dagger}$ Vadim Y. Arshavsky, ${ }^{2}$ and Eduardo Solessio ${ }^{1}$ \\ ${ }^{1}$ Center for Vision Research and State University of New York (SUNY) Eye Institute, Department of Ophthalmology, SUNY Upstate Medical University, \\ Syracuse, New York 13210, ${ }^{2}$ Albert Eye Research Institute, Duke University Medical Center, Durham, North Carolina 27710, and ${ }^{3}$ Department of \\ Biochemistry and Molecular Biology, Virginia Commonwealth University, Richmond, Virginia 23298
}

The rate at which photoreceptors recover from excitation is thought to be critical for setting the temporal resolution of vision. Indeed, mutations in RGS9 (regulator of G-protein signaling 9) and R9AP (RGS9 anchor protein) proteins mediating rapid photoresponse recovery impair patients' ability to see moving objects. In this study, we analyzed temporal properties of retinal sensitivity and spatiotemporal aspects of visual behavior in R9AP knock-out mice. Surprisingly, we have found that this knock-out does not affect dim-light vision mediated by rods acting as single-photon counters. Under these conditions, vision was also unaffected in mice overexpressing R9AP in rods, which causes accelerated photoresponse recovery. However, in brighter light, slow photoresponse recovery in rods and cones impaired visual responses to high temporal frequency stimuli, as reported for the daylight vision of human patients. Therefore, the speed of photoresponse recovery can affect temporal resolution and motion detection when photoreceptors integrate signals from multiple photons but not when they act as single-photon counters.

\section{Introduction}

The first steps in vision take place in rod and cone photoreceptors that generate electrical signals in response to light. The underlying molecular process, known as phototransduction, consists of a series of well-coordinated biochemical reactions that ultimately control the membrane potential of the photoreceptor cell. The shape of a light response (a "photoresponse") depends on the rates at which phototransduction proteins are activated by light and the rates at which they are subsequently inactivated (for detailed reviews, see Burns and Baylor, 2001; Fain et al., 2001; Arshavsky et al., 2002; Fu and Yau, 2007; Burns and Pugh, 2010). The critical role of photoreceptors in the visual system makes it important to understand how the kinetics of the photoresponse translates into overall visual sensitivity and performance.

Abnormal rates of photoreceptor recovery impair vision (Dryja, 2000; Burns and Pugh, 2010). For example, patients suffering from bradyopsia, a condition arising from recessive muta-

Received March 15, 2012; revised Aug. 15, 2012; accepted Aug. 19, 2012.

Author contributions: Y.U., R.H., C.-K.C., R.B.B., V.Y.A., and E.S. designed research; Y.U. and R.H. performed research; Y.U., R.H., V.Y.A., and E.S. analyzed data; Y.U., R.H., V.Y.A., and E.S. wrote the paper.

*These authors contributed equally to this study.

${ }^{\dagger}$ Deceased, December 24, 2009.

This work was supported by National Institutes of Health Grants EY00067 (R.B.B.), EY12859 (V.Y.A.), EY10336 (V.Y.A.), and EY5722 (to Duke University), unrestricted grants from Research to Prevent Blindness to State University of New York Upstate Medical University and Duke University, and the Lions of Central New York. We dedicate this work to Dr. R. B. Barlow. We thank Dr. L. J. Frishman (University of Houston, Houston, TX) for critically reading this manuscript.

Correspondence should be addressed to either of the following: Vadim Arshavsky, Duke University Medical Center, Albert Eye Research Institute, Room 5012, 2351 Erwin Road, Box 3802, Durham, NC 27710, E-mail: vadim.arshavsky@duke.edu; or Eduardo Solessio, Center for Vision Research and State University of New York (SUNY) Eye Institute, Department of Ophthalmology, SUNY Upstate Medical University, 3255A Weiskotten Hall, 766 Irving Avenue, Syracuse, NY 13210, E-mail: solessie@upstate.edu.

DOI:10.1523/JNEUROSCI.1296-12.2012

Copyright $\odot 2012$ the authors $\quad 0270-6474 / 12 / 3214364-10 \$ 15.00 / 0$ tions in RGS9 (regulator of G-protein signaling 9) or R9AP (RGS9 anchor protein) genes, have difficulties tracking moving objects and adjusting to sudden changes in ambient light intensities (Nishiguchi et al., 2004). RGS9 is a GTPase activating protein responsible for the rapid inactivation of the phototransduction G-protein transducin (He et al., 1998). In photoreceptors, RGS9 exists as a complex with its constitutive G $\beta 5$ subunit (Makino et al., 1999) and is tethered to photoreceptor membranes by the anchor protein R9AP (Hu and Wensel, 2002). Importantly, the expression level of R9AP determines the cellular amount of the entire RGS9:G $\beta 5$ :R9AP complex: R9AP knockout causes complete elimination of RGS9 (Keresztes et al., 2004), whereas R9AP overexpression results in a several-fold increase in RGS9 and G $\beta 5$ levels (Krispel et al., 2006). Accordingly, both RGS9 and R9AP knock-outs in mice cause slow photoresponse recovery in both rods and cones (Chen et al., 2000; Lyubarsky et al., 2001; Keresztes et al., 2004), whereas RGS9 overexpression in rods accelerates this rate by several-fold (Krispel et al., 2006).

In this study, we explored the relationship between the rate of photoresponse recovery and the spatiotemporal properties of vision using two animal models, R9AP knock-out $\left(R 9 A P^{-/-}\right)$mice lacking the RGS9:G $\beta 5$ :R9AP complex in both rods and cones and mice overexpressing this complex in rods. We analyzed the ability of animals to detect moving gratings (Prusky et al., 2004; Umino et al., 2008) and to respond to flickering light stimuli (Krishna et al., 2002; Shirato et al., 2008) to determine contrast sensitivity of their visual responses (Shapley and Enroth-Cugell, 1984). Contrast sensitivity is a fundamental property of vision providing the measure of the lowest contrast detectable in an image and thereby defining our ability to perform everyday activities (West et al., 2002). To our great surprise, neither slowdown nor acceleration of photoresponse recovery altered temporal contrast sensitivity 
in dim light at which visual inputs are conveyed by rods acting as single-photon counters. However, under conditions of moderate or bright illumination, when both photoreceptor types process multiple photon inputs, mice lacking the RGS9:G $\beta 5$ :R9AP complex experienced a profound loss in sensitivity to high temporal frequency stimuli.

\section{Materials and Methods}

Animal strains. $R 9 A P^{-/-}$mice (Keresztes et al., 2004) were bred with C57BL/6 wild-type (WT) mice, and the heterozygous offspring was used to produce $R 9 A P^{-/-}$and $R 9 A P^{+/+}$littermates used in all experiments. R9AP-overexpressing (R9AP-OE) mice (line R9AP95) are described by Krispel et al. (2006). The expression level of RGS9 in their rods was approximately threefold higher than in WT controls (Krispel et al., 2006). Animals of either sex were tested, and their ages ranged from 2 to 6 months. Mice were maintained on a $14 / 10$ h light/dark cycle, darkadapted overnight before experiments, and tested during the subjective day.

ERG recordings. ERGs were recorded using the Espion $\mathrm{E}^{2}$ system and a ColorDome ganzfeld stimulator (Diagnosys) as described by Herrmann et al. (2010, 2011). Briefly, mice were dark-adapted and prepared for recordings using infrared goggles. Mice were anesthetized by intraperitoneal injection of a ketamine/xylazine mixture $(85$ and $10 \mathrm{mg} / \mathrm{kg}$, respectively), and pupils were dilated with $1 \%$ cyclopentolate- $\mathrm{HCl}$ and $2.5 \%$ phenylephrine. A drop of Gonak solution (Akorn) was placed on the cornea. Recordings were performed from both eyes with silver loop electrodes supplemented with contact lenses to keep the eyes immersed in Gonak solution to minimize cataract development. The reference electrode was a toothless alligator clip wetted with Gonak and attached to the mouse cheek. Mouse body temperature was maintained at $37^{\circ} \mathrm{C}$ using a water-based warming pad. Flicker ERGs were evoked by sinusoidal monochromatic light stimulus (465 nm) at various mean retinal illuminance $\left(1.85 \times 10^{-3}\right.$ to 18.5 Trolands), contrasts (5-100\%), and temporal frequencies $(3,4.5,6,9$, and $12 \mathrm{~Hz})$. Each response is the average of 30 trials. ERG responses were analyzed by Fourier transformation using the MATLAB software (MathWorks). The magnitude of the fundamental component (response at the stimulus frequency) was plotted as a function of contrast, and the data were fitted with a power law:

$$
y=a \times x^{b},
$$

where $y$ is the amplitude of the flicker ERG fundamental component, $x$ is modulation contrast, and $a$ and $b$ are fitting parameters.

As demonstrated previously (Shirato et al., 2008), flicker ERG responses in mice exposed to light intensities of at least 400 Trolands (brighter light than used in any of our experiments) originate primarily from the activity of bipolar cells with little or no direct contributions from photoreceptors. Furthermore, any ERG responses in the dim light range used in our study photoexciting between 0.4 and $7 \mathrm{R}^{\star} / \mathrm{rod} / \mathrm{s}$ are thought to originate exclusively from rod bipolar cells. This is because these intensities are (1) well above the levels at which the positive scotopic threshold response dominates the ERG response $\left(0.01 \mathrm{R}^{\star} /\right.$ rod; Saszik et al., 2002), (2) below the level necessary to induce responses from cone bipolar cells (10 R*/rod; Abd-El-Barr et al., 2009), and (3) rod a-wave contributions at these light intensities are too small to be detected (Herrmann et al., 2010).

Measuring contrast sensitivity of the optomotor responses. We measured contrast sensitivities by observing the reflexive optomotor behavior of mice to rotating gratings, using the OptoMotry apparatus (Prusky et al., 2004) and methodology reported previously (Umino et al., 2008). Briefly, dark-adapted mice were placed on a pedestal located at the center of an enclosure formed by four video monitors that display the stimulus gratings. Head movements of mice were monitored by an observer using infrared illumination and a video camera positioned above the animal. The observer could see only the animal and not the rotating pattern. The optomotor stimulus consisted of a vertically oriented sinusoidal pattern that rotated for $5 \mathrm{~s}$ periods. The direction of rotation was random. The observer selected the direction of rotation based on the mouse movements and received auditory feedback indicating correct or incorrect
Table 1. Parameters used to fit the optomotor contrast sensitivity functions of $R 9 A P^{+/+}, R 9 A P^{-/-}$, R9AP-0E, and R9AP-0E-CTL mice with the filter model as expressed in Equation 2

\begin{tabular}{|c|c|c|c|c|c|}
\hline $\begin{array}{l}\text { Illuminance } \\
\text { (Trolands) }\end{array}$ & Genotype & $\begin{array}{l}k \\
\left(\mathrm{~Hz}^{-1}\right)\end{array}$ & $\begin{array}{l}f_{\text {so }} \\
\text { (cycles } /^{\circ} \text { ) }\end{array}$ & $\begin{array}{l}f_{\text {to }} \\
(\mathrm{Hz})\end{array}$ & $\begin{array}{l}S_{p o} \\
(\% / s)\end{array}$ \\
\hline \multirow[t]{3}{*}{8} & $R 9 A P^{+/+}$ & 29 & 0.2 & 12.0 & 15.0 \\
\hline & $R 9 A^{-1-}$ & 29 & 0.3 & 0.8 & 20.0 \\
\hline & R9AP-OE R9AP-OE-CTL & 34 & 0.23 & 12.0 & 15.0 \\
\hline \multirow[t]{2}{*}{$8 \times 10^{-5}$} & $R 9 A P^{+/+} R 9 A P^{-/-}$ & 16 & 0.3 & 0.8 & 80.0 \\
\hline & R9AP-OE R9AP-OE-CTL & 13.3 & 0.3 & 1.2 & $80.0^{a}$ \\
\hline
\end{tabular}

${ }^{a}$ The value of $s_{p o}$ was $15.0 \%$ at 0.031 cycles ${ }^{\circ}$.

determination. Based on a two-alternative forced-choice method, the computer changed the contrast of the stimulus following a staircase paradigm and converged on to a threshold arbitrarily defined as $70 \%$ correct responses (Prusky et al., 2004). Contrast sensitivities were measured over an 8-log unit range of luminance, with the maximum mean luminance of $70 \mathrm{~cd} / \mathrm{m}^{2}$ (equivalent to retinal illuminance of 8 scotopic Trolands in mice with non-dilated pupils). Spatial frequencies of the stimulus grating (from 0.031 to $0.383 \mathrm{cycles}^{\circ}{ }^{\circ}$ ) and speeds of rotation (from 0.5 to $48^{\circ} / \mathrm{s}$ ) were varied independently. Responses of $R 9 A P^{-/-}$mice to gratings with the spatial frequency of or below 0.031 cycles $/{ }^{\circ}$ were weak and highly variable, so they could not be studied reliably.

Analytical model. The contrast sensitivity functions obtained by the behavioral assay were fitted using the expression derived by Umino et al. (2008) who models visual contrast sensitivity, $G\left(f_{s}, f_{t}, s_{p}\right)$, in mouse with a series of spatial, temporal, and speed filters:

$$
G\left(f_{s}, f_{t}, s_{p}\right)=\frac{k f_{t}}{\left(1+\left(f_{s} / f_{s o}\right)^{2}\right)^{2}\left(1+\left(f_{t} / f_{t o}\right)^{2}\right)\left(1+\left(s_{p} / s_{p o}\right)^{2}\right)},
$$

where $f_{s}$ is the spatial frequency (in cycles per degree), $f_{t}$ is the temporal frequency (in Hertz), and $s_{p}$ is grating speed (degrees per second). The $k f_{t}$ term in the numerator accounts for the observed direct proportionality between sensitivity and temporal frequency. The three low-pass terms in the denominator express the reduction in sensitivity that is observed when $f_{s}, f_{t}$, or $s_{p}$ increase past a critical value defined by $f_{s o}, f_{t o}$, and $s_{p . o .}$, respectively. The speed of rotation $s_{p}$ relates to the two independent variables $f_{s}$ and $f_{t}$ as $f_{t}=s_{p} f_{s}$. The values of the scaling factor $k$ and the parameters $f_{s o}, f_{t o}$, and $s_{p o}$ listed in Table 1 were determined empirically using the approach outlined by Umino et al. (2008). Equation 2 along with the parameters listed in Table 1 was used to generate the curves in Figures 3 and 6.

The relative contrast sensitivity functions in Figure $4 B$ were fit with a first-order low-pass filter approximation (Stockman et al., 2006):

$$
S_{R}=\frac{S_{R \max }}{\left(1+\left(f_{t} / f_{c}\right)^{2}\right)^{0.5}}
$$

where $S_{R}$ is the relative sensitivity, $f_{t}$ is the temporal frequency of the stimulus, $S_{R \max }$ is a scaling constant, and $f_{c}$ is the temporal cutoff frequency, such that $S_{R}=0.7 \times S_{R \max }$ when $f_{t}=f_{c}$. Fits were performed using a sum of squares minimization routine. Errors in the calculated ratios between contrast sensitivities of $R 9 A P^{-1-}$ and $R 9 A P^{+/+}$mice and between R9AP-OE and R9AP-OE control mice were propagated as the sum of the squared relative SDs. Error bars in the plot represent the SEM.

Conversion from luminance to the rate of rhodopsin excitation. The rate of rhodopsin photoexcitation was determined in anesthetized mice with fully dilated pupils as described previously (Lobanova et al., 2007). The amount of rhodopsin bleached by steady illumination was determined in extracted retinas by difference spectroscopy at $500 \mathrm{~nm}$ before and after rhodopsin regeneration with 11-cis-retinal (Sokolov et al., 2002). The rate of rhodopsin isomerization in rods was calculated by multiplying the fraction of photoactivated rhodopsin by the total number of rhodopsin molecules per mouse rod $\left[7 \times 10^{7}\right.$ from Lyubarsky et al. (2004)] and dividing this product by the duration of background illumination. For 
A

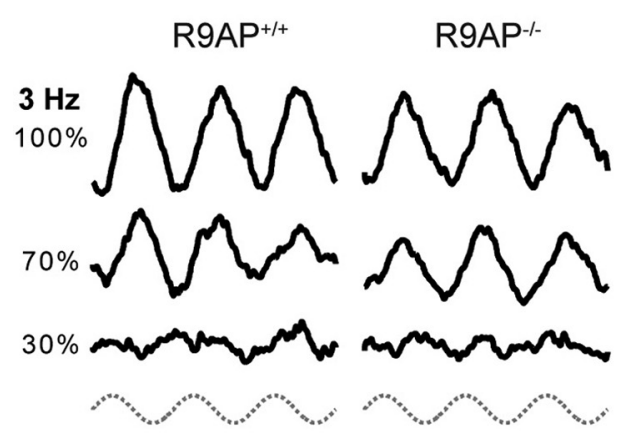

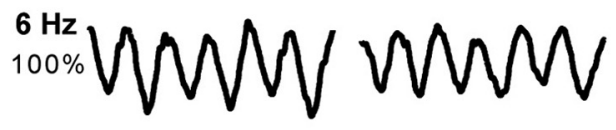

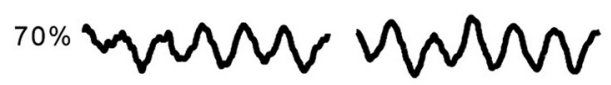

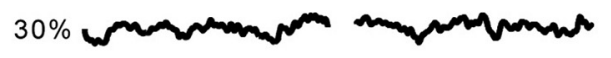

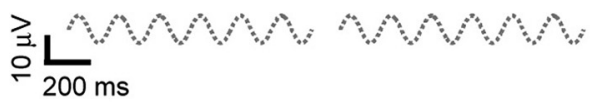

B 18.5 Trolands
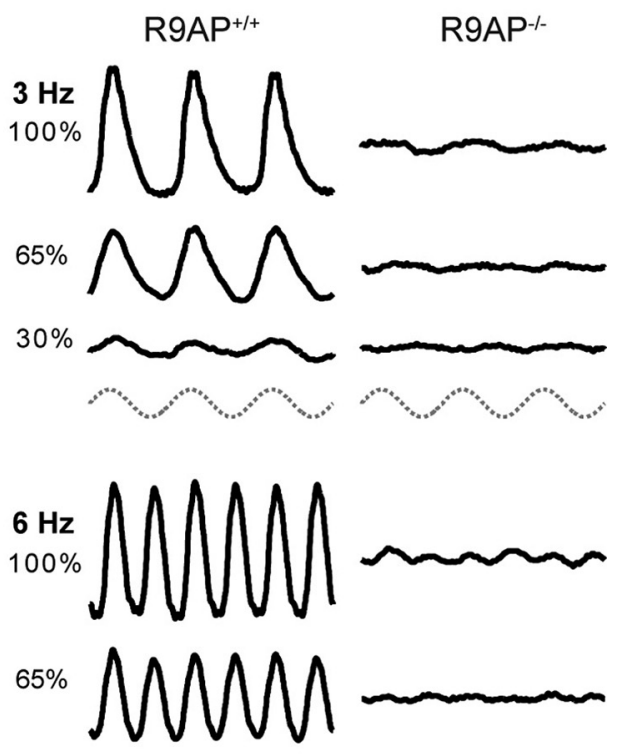

$30 \%$

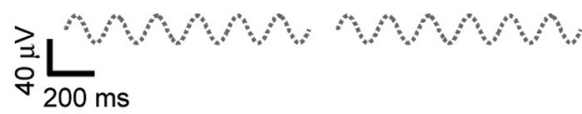

Figure 1. Flicker ERG responses in $R 9 A P^{-/-}$and $R 9 A P^{+/+}$mice. Representative flicker ERG recordings from $R 9 A P^{+/+}$and $R 9 A P^{-/-}$mice were obtained at the illuminance of $7.4 \times 10^{-3}$ Trolands producing $\sim 1.5 \mathrm{R}^{*} / \mathrm{rod} / \mathrm{s}(\boldsymbol{A})$ and 18.5 Trolands producing $\sim 3900 \mathrm{R}^{*} / \mathrm{rod} / \mathrm{s}(\boldsymbol{B})$. Traces are averages among 30 individual trials in response to sinusoidal, full-field stimuli represented by the gray dotted lines. The values of contrast and flicker frequencies are shown.

our ERG setup, we determined that background light of $1 \mathrm{~cd} / \mathrm{m}^{2}$ generated $800 \mathrm{R}^{\star} / \mathrm{rod} / \mathrm{s}$.

To directly compare the light sensitivities of ERG and behavioral responses, we accounted for the pupillary reflexes by determining the amount of light reaching the retina. Retinal illuminance (in scotopic Trolands) was defined as the product of the scotopic luminance at the cornea (in candelas per square meter) multiplied by the area of the pupil ( $A$; square millimeters). Accordingly, the luminance of $1 \mathrm{~cd} / \mathrm{m}^{2}$ in anesthetized mice with fully dilated pupils $\left(A=3.8 \mathrm{~mm}^{2}\right)$ corresponded to 3.8 Trolands. Pupil diameters, $d$, in unrestrained mice used in behavioral assays were measured using an infrared camera placed inside of the OptoMotry unit, after mice were exposed to sinusoidal gratings presented at various light intensities. Gratings were presented with a spatial frequency of $0.03 \mathrm{cycles} /{ }^{\circ}$ and a speed of $12 \%$ with $100 \%$ contrast. Pupil areas were calculated as $A=\pi d^{2} / 4$. Small errors introduced by slightly closed eyelids that cover the pupil in freely behaving mice were not accounted for in the calculations.

\section{Results}

Choice of the primary animal model

Complete inactivation of the RGS9:G $\beta 5$ :R9AP complex in mice could be achieved by knocking out any of its constitutive components (Chen et al., 2000, 2003; Keresztes et al., 2004). This provided three options for choosing an animal model displaying slowly inactivating photoresponses. We ruled out $G \beta 5^{-/-}$mice because of severe retinal dysfunction originating at sites downstream from photoreceptors (Rao et al., 2007). A concern about the RGS9 knock-out is that it causes locomotor deficiencies that could potentially interfere with our behavioral assay because of the lack of RGS9 expression in the striatum (Rahman et al., 2003; Blundell et al., 2008). In contrast, R9AP is expressed exclusively in the retina (Cao et al., 2009), making $R 9 A P^{-1-}$ mice a more attractive choice. A potential concern regarding these mice is that R9AP knock-out causes a small, typically $<15 \mathrm{~ms}$, delay in the early stage of bipolar cell responses, as revealed by recording ERG b-waves reflecting light-dependent ON-bipolar cell depolarization in vivo (Jeffrey et al., 2010). This delay was attributed to R9AP expression in the dendritic tips of ON-bipolar cells in which it forms a complex with G $\beta 5$ and RGS11, another member of the RGS family (Morgans et al., 2007; Cao et al., 2009; Mojumder et al., 2009; Chen et al., 2010). However, a recent side-by-side comparison of ERG b-waves recorded from R9AP and RGS9 knock-out mice revealed the presence of a comparable delay in both animals (Herrmann et al., 2011), making them an equal choice in the context of the present study. Based on these considerations, we chose to use $R 9 A P^{-1-}$ mice as the primary experimental model.

\section{Temporal contrast sensitivity of ERG responses in R9AP} knock-out mice

We first analyzed temporal processing of visual information in $R 9 A P^{-1-}$ mice by recording flicker ERGs. In mice exposed to light intensities from the range used in our study, flicker ERG reflects primarily the activity of bipolar cells, with little direct contributions from photoreceptors (Shirato et al., 2008; see Materials and Methods). Responses were evoked by sinusoidal fullfield stimulation of various mean illuminances, temporal frequencies, and contrasts (the latter defined as the relative difference between light and dark levels of the stimulus). Surprisingly, recordings obtained in very dim retinal illumination, such as in a representative experiment at the mean illuminance of $7.4 \times 10^{-3}$ Trolands (Fig. $1 \mathrm{~A}$ ), did not reveal any notable R9AP knock-out phenotype. This was strikingly different from the data obtained at higher light intensities, at which response amplitudes of $\mathrm{R} \mathrm{AP} \mathrm{P}^{-/-}$mice were barely detected at high-contrast stimula- 

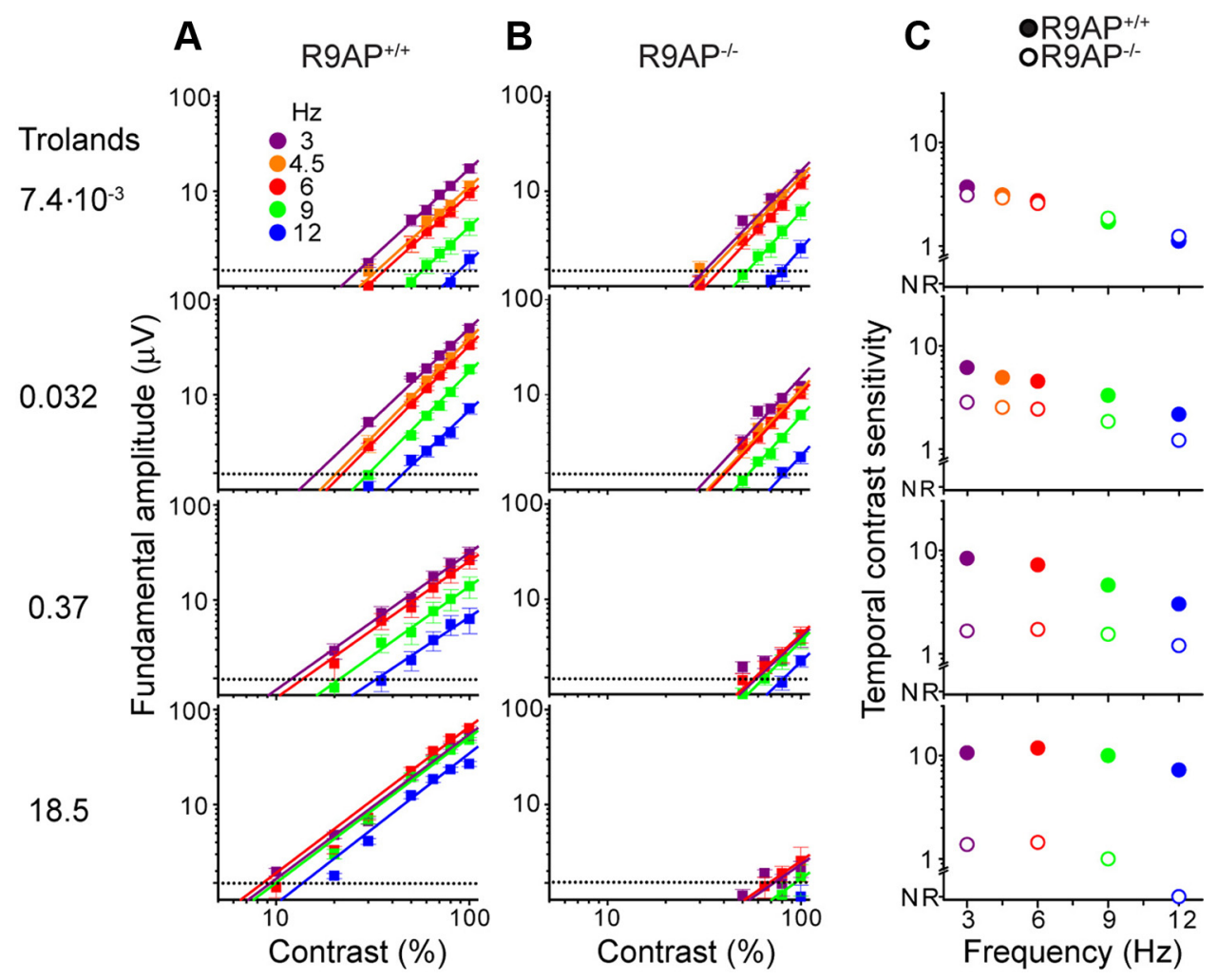

Figure 2. The effects of R9AP knock-out on temporal contrast sensitivity of flicker ERGs at various light intensities. $A, B$, Magnitude of the fundamental component of flicker ERGs is plotted as a function of stimulus contrast at various flicker frequencies for $R_{9 A P^{+/+}}(\boldsymbol{A})$ and $R 9 A P^{-/-}(\boldsymbol{B})$ mice. Data points represent mean \pm SEM; $n$ varied between 6 and 10 for each mouse type. Data were fitted to Equation 1 (see Materials and Methods). ERG contrast threshold, defined as the contrast at which the response was $1.5 \mu \mathrm{V}$, is indicated with dotted lines. $C$, Temporal contrast sensitivity (the inverse of contrast required to reach the $1.5 \mu \mathrm{V}$ threshold determined from $\boldsymbol{A}$ and $\boldsymbol{B}$ ) as a function of flicker frequency in $R 9 A \mathrm{P}^{+/+}$(filled symbols) and $R 9 A \mathrm{P}^{-/-}$(open symbols) mice.

tion and essentially abolished at low-contrast stimulation (e.g., at 18.5 Trolands; Fig. $1 \mathrm{~B}$ ).

To analyze these data quantitatively, we applied Fourier analysis to determine the magnitude of the flicker ERG at the frequency of the light stimulus, called the fundamental component. This approach improves discrimination of small signals from background noise (Krishna et al., 2002) and allows signals generated mainly by bipolar cells and photoreceptors to be distinguished from those generated farther downstream in the retina (Bush and Sieving, 1996; Shirato et al., 2008). Figure 2, $A$ and $B$, shows the dependencies of the fundamental components on stimulus contrast at four selected light intensities. Data were collected at several temporal frequencies, and the resulting plots were fitted by straight lines on the log/log scale (Wu and Burns, 1996). Each plot was used to estimate the temporal contrast sensitivity (Fig. 2C), defined as the inverse of the contrast required to evoke a threshold response of $1.5 \mu \mathrm{V}$-an arbitrarily chosen magnitude value just above the noise level (note that the actual threshold value does not have a bearing on the conclusion drawn from these experiments because the lines in Fig. 2, $A$ and $B$, are parallel to one another).

Consistent with the example shown in Figure $1 A$, contrast sensitivities of $R 9 A P^{-/-}$mice and their WT littermates $\left(R 9 A P^{+/+}\right)$were essentially identical at light intensities up to $7.4 \times 10^{-3}$ Trolands. Under these conditions, rods operate as single-photon counters (e.g., $\sim 1.5$ photoexcited rhodopsin molecules $\left(\mathrm{R}^{*}\right)$ per second are produced in each rod at $7.4 \times 10^{-3}$ Trolands), and flicker ERGs originate entirely from the activity of rod bipolar cells. However, increased light intensity affected contrast sensitivities of these mice differently. Although the contrast sensitivity of $\mathrm{RAAP}^{+/+}$mice increased with increasing retinal il- luminance, $R 9 A P^{-1-}$ mice displayed an opposite trend, showing a mild reduction in sensitivity at 0.032 Trolands (exciting $7 \mathrm{R}^{\star}$ / $\mathrm{rod} / \mathrm{s}$ ) and a major reduction in brighter light. These data indicate that slow photoresponse recovery impairs the temporal resolution of flicker ERG responses at light intensities exceeding the level at which WT rods function as single-photon counters.

Such a contrast sensitivity reduction in $R 9 A P^{-/-}$rods could be either a direct consequence of slow photoresponse recovery or it could be an indirect effect of enhanced photoreceptor desensitization attributable to each photon evoking a larger response in these mice. Indeed, single-photon responses of $R 9 A P^{-1-}$ rods have larger amplitudes ( 0.54 vs $0.34 \mathrm{pA})$ and extended integration times $\left(2.2\right.$ vs $0.2 \mathrm{~s}$ ) than $R 9 A P^{+/+}$rods (Keresztes et al., $2004)$. Together, these two parameters yield $\sim 13$-fold larger elementary photoresponses in $R 9 A P^{-1-}$ rods (estimated as described by Baylor and Hodgkin, 1973; Nakatani et al., 1991). When these responses are integrated on sustained light exposure of a given light intensity, $R 9 A P^{-/-}$rods respond as if they were exposed to $\sim 13$-fold brighter light. In other words, $R 9 A P^{-/-}$ rods receive a 13-fold brighter equivalent background light than $R 9 A P^{+/+}$rods. This is predicted to result in a higher degree of their light-induced desensitization and photoresponse compression than in $R 9 A P^{+/+}$rods. To assess the contribution from such a photoreceptor response compression on the flicker ERG phenotype in Figure 2, we compared ERG responses of $R 9 A P^{+/+}$ mice recorded at 0.032 and 0.37 Trolands (an $\sim 12$-fold higher illumination). Contrary to the contrast sensitivity reduction caused by this light intensity change in $R 9 A P^{-/-}$mice, the contrast sensitivity of flicker ERGs of $R 9 A P^{+/+}$mice was increased. Therefore, we conclude that the major impairment of temporal 
signal processing in $R 9 A P^{-/-}$mice revealed in our experiments originates primarily from the slow photoresponse recovery and not from the photoresponse desensitization by enlarged elementary responses.

\section{Contrast sensitivity and tuning properties of behavioral responses in R9AP knock-out mice}

We next investigated the visual performance of $R 9 A P^{-1-}$ mice behaviorally by monitoring the optomotor reflex (rotation of the body and head of a mouse as it tracks a moving object) to sine-wave gratings presented at various speeds of motion and spatial frequencies (Prusky et al., 2004). The two independent variables were spatial and temporal frequencies of the moving gratings. Spatial frequency is the number of dark/light cycles per degree of visual angle. Temporal frequency is the number of cycles per second "viewed" by a single photoreceptor as the grating moves across the visual field; it is calculated by multiplying spatial frequency by the speed of motion and defined in units of degrees rotated per second.

Contrast changes in the visual environment are perceived most effectively when they occur at optimal spatial and temporal frequencies. Accordingly, testing contrast sensitivity at multiple spatial or temporal frequencies in both animals and humans produces bell-shaped, bandpass, contrast sensitivity functions (Pasternak and Merigan, 1981). Dim-light vision supported exclusively by rods yields contrast sensitivity functions that are "temporally tuned" (Umino et al., 2008): they peak at the same temporal frequency $(\sim 0.75 \mathrm{~Hz}$ in mice) regardless of the spatial frequency (Fig. $3 A$ ). In other words, contrast sensitivity is the highest when low spatial frequency gratings move faster or higher spatial frequency gratings move slower. At higher light intensities, contrast sensitivity functions are "speed tuned" (Umino et al., 2008): moving gratings are best detected at an optimal speed $(\sim 12 \%$ in mice), regardless of spatial frequency of the gratings (Fig. $3 G$ ). Figure 3 further illustrates another property of contrast sensitivity functions: when they are temporally tuned (Fig. $3 A$ ), the corresponding speed sensitivity functions do not line up (Fig. 3C). Analogously, contrast sensitivity functions tuned to speed (Fig. 3G) cannot be simultaneously tuned to temporal frequency (Fig. $3 E$ ).

Consistent with the ERG results in Figure 2, $R 9 A P^{-/-}$mice did not display any significant alteration in contrast sensitivity under conditions when rods act as single-photon counters (e.g.,
$8 \cdot 10^{-5}$ Trolands
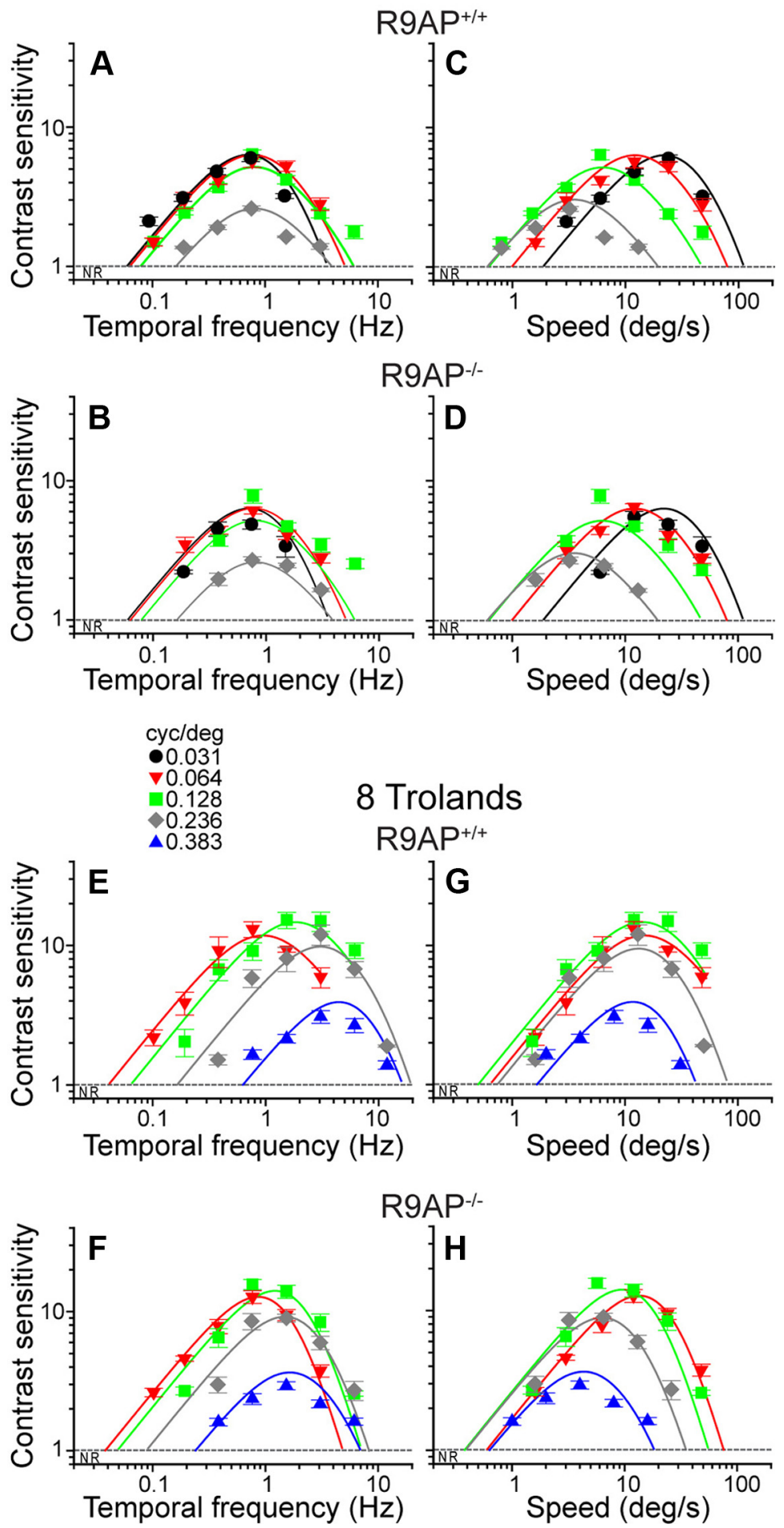

Figure 3. The effects of R9AP knock-out on contrast sensitivity and tuning of behavioral responses. Families of temporal and speed contrast sensitivity functions of $R 9 \mathrm{AP}^{+/+}$and $R 9 A \mathrm{P}^{-/-}$mice obtained with the optomotor response assay at various spatial frequencies (cycles per degree indicated in the figure). Sensitivities were determined at $8 \times 10^{-5}$ (producing 0.02 $\mathrm{R}^{*} / \mathrm{rod} / \mathrm{s}$ ) and at 8 Trolands ( $1650 \mathrm{R}^{*} / \mathrm{rod} / \mathrm{s}$ ). Continuous lines represent fits of the data to Equation 2 (see Materials and Methods). Fitting parameters are listed in Table $1 ; R^{2}>0.85$ in plots $\boldsymbol{A}, \boldsymbol{C}$, and $\boldsymbol{E}-\boldsymbol{H}$ and $R^{2}=0.7$ for $\boldsymbol{B}$ and $\boldsymbol{D}$. Data points represent mean \pm $\mathrm{SEM} ; n$ varied between 4 and 6 for $R 9 A P^{+/+}$mice and between 8 and 12 for $R 9 A P^{-1-}$ mice. NR, No optomotor response.

at $8.0 \times 10^{-5}$ Trolands activating $\sim 0.02 \mathrm{R}^{\star} / \mathrm{rod} / \mathrm{s} ;$ Fig. $\left.3 B, D\right)$. To better illustrate this point, we calculated the ratios between contrast sensitivities of $R 9 A P^{-/-}$and $R 9 A P^{+/+}$mice obtained at var- 


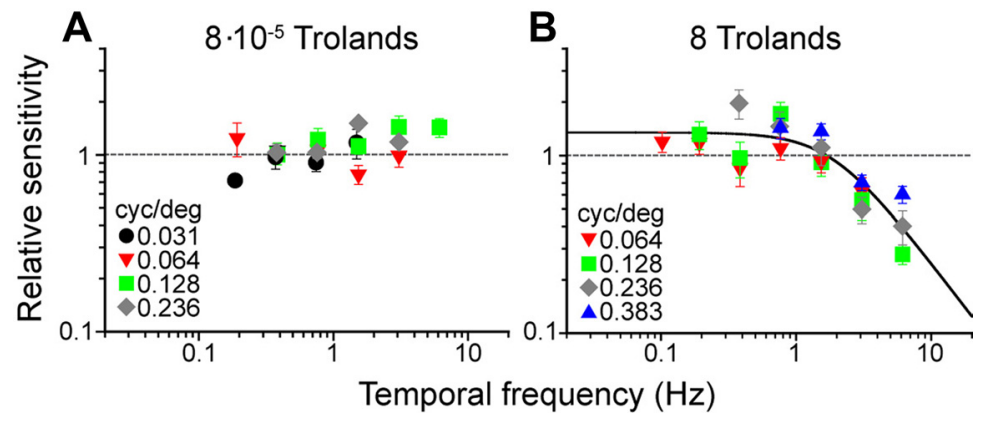

Figure 4. The contrast sensitivity reduction in $R 9 A P^{-1-}$ mice exposed to light of high intensity is caused by a loss in sensitivity to temporal frequencies $>1.5 \mathrm{~Hz}$. The relative contrast sensitivity functions at $8 \times 10^{-5}$ Trolands $(0.02 \mathrm{R} / \mathrm{rod} / \mathrm{s})(\boldsymbol{A})$ and 8 Trolands $\left(1650 \mathrm{R}^{*} / \mathrm{rod} / \mathrm{s}\right)(\boldsymbol{B})$ were determined as the ratio between the contrast sensitivities of $R 9 A P^{-/-}$and $R 9 A P^{+/+}$mice at individual spatial and temporal frequencies from Figure 3. Data in $\boldsymbol{B}$ were fit with a first-order low-pass function (Eq. 3; see Materials and Methods) with a maximal sensitivity $S_{R \max }$ of 1.3 and a cutoff frequency $f_{c}$ of $1.8 \mathrm{~Hz}\left(R^{2}=0.7\right)$.

ious temporal frequencies (Fig. 4A) and found that each ratio remained close to unity.

Interestingly, a similar result was obtained in experiments analyzing visual contrast sensitivity in mice overexpressing R9AP in rods. Rods of these mice contain threefold to fourfold more RGS9:G $\beta 5$ :R9AP complex than in normal animals, which causes an $\sim 2.5$-fold increase in the recovery rate of their photoresponses (Krispel et al., 2006). Nevertheless, the analysis of their rod-driven flicker ERG responses in very dim light did not reveal any effects on response amplitudes and contrast sensitivities (Fig. 5). Similarly, behavioral contrast sensitivity functions of rod-do-

minant vision in R9AP-OE animals were normal (Fig. 6).

In brighter light, behavioral responses were markedly altered by the R9AP knock-out. Contrast sensitivities were reduced at temporal frequencies exceeding $\sim 1.5 \mathrm{~Hz}$ (Fig. $3 F$ ), which is particularly evident from the relative contrast sensitivity plot (Fig. $4 B)$. Accordingly, a nearly perfect speed tuning observed in $R 9 A P^{+/+}$mice (Fig. 3G) was distorted in $R 9 A P^{-/-}$mice (Fig. $3 H)$, whereas the temporal sensitivity functions of $R 9 A P^{-/-}$mice were closer to one another than in the $R 9 A P^{+/+}$control (Fig. 3, compare $E, F)$. This result indicates that, at high illumination levels, the reduction in photoresponse inactivation rate caused by the R9AP knock-out impedes the processing of high temporal frequencies.

\section{Reconciliation of ERG and behavioral data}

The two techniques used in our study address different aspects of visual function. Flicker ERGs originate from the retina and reflect primarily the activity of bipolar cells and photoreceptors (Shirato et al., 2008). Behavioral optomotor assays represent much more complex visual processing, integrating primarily the activities of the retina and subcortical pathways (Douglas et al., 2005). To make a quantitative comparison of ERG and behavioral data, we measured contrast sensitivities by each technique over a broad range of illumination at the same temporal frequency of $3 \mathrm{~Hz}$. This frequency is sufficiently high to observe a strong drop in contrast sensitivity of cone-driven responses in $R 9 A P^{-1-}$ mice, yet it is low enough to record robust behavioral responses in $\mathrm{dim}$ light. Spatial frequency in behavioral experiments was set at 0.128 cycles $/{ }^{\circ}$, which preserves high contrast sensitivity over the entire light intensity range used.

Such a comparative analysis required the measurement of illumination reaching the retina surface (expressed in units of Trolands). This is because mice subjected to ERG recordings were anesthetized with their pupils dilated and not responding to light, whereas pupils of the freely behaving mice were not dilated and responded to changes in light levels. We therefore measured the steady-state pupil areas in each case, following the protocols described in Materials and Methods (Fig. 7). We anticipated that the pupillary reflex in $R 9 A P^{-/-}$mice would be more light-sensitive than normal as a result of increased integration times of photoresponses caused by this knock-out. Indeed, we have found that, in the luminance range between $10^{-4}$ and $10^{-1} \mathrm{~cd} /$ $\mathrm{m}^{2}$, the pupillary reflex in $R 9 A P^{-/-}$mice was $\sim 20$-fold more sensitive to light than in their $\mathrm{R} \mathrm{AP} \mathrm{P}^{+/+}$littermates. After converting light intensities used in ERG and behavioral assays into Trolands, we plotted the values of contrast sensitivities obtained by each technique on the same graph (Fig. 8). In addition, the ordinate for the ERG plot was scaled to attain the best match between the trends of the plots.

The light-dependency patterns of ERG and behavioral plots in Figure 8 followed similar general trends for each mouse type. Although plots obtained for $R 9 A P^{+/+}$mice displayed monotonic functions (saturating at $\sim 10 \mathrm{R}^{\star} / \mathrm{rod} / \mathrm{s}$ for the behavioral plot and continue rising above that intensity for the ERG plot), plots from $R 9 A P^{-1-}$ mice had more complex shapes. They overlapped with plots obtained for $R 9 A P^{+/+}$mice until the light intensity reached the level producing $\sim 10 \mathrm{R}^{\star} / \mathrm{rod} / \mathrm{s}$, but dropped by approximately threefold at brighter light intensities. These data further support our conclusion that the rate of photoresponse recovery becomes critical for setting the temporal resolution of visual behavior when light intensity exceeds the level at which WT rods operate at the single-photon counting regimen.

\section{Discussion}

In this study, we combined ERG recordings with optomotor behavior assays to investigate how an altered rate of photoresponse recovery affects temporal contrast sensitivity of visual function. We have found that this rate is critical for setting the temporal resolution of vision under conditions of moderate to bright illumination but not in dim light when vision is driven by rods acting as single-photon detectors. This result has important implications for our understanding of the temporal resolution of vision, as detailed below.

\section{Photoresponse recovery does not affect temporal contrast sensitivity in the single-photon counting regimen}

Our first major result is that, under conditions of dim illumination that favor rod-dominant vision ("scotopic conditions"), the temporal properties of both flicker ERGs and optomotor behavior were unaffected by the R9AP knock-out. This is despite the fact that the rate of photoresponse recovery in $R 9 A P^{-1-}$ rods is slowed by $>10$-fold (Keresztes et al., 2004). Dark-adapted rods are extraordinarily sensitive to light, which enables them to signal the absorption of single photons (Hecht et al., 1942). These single-photon responses follow a highly reproducible time course (Baylor et al., 1979; Rieke and Baylor, 1998; Whitlock and Lamb, 1999), with their rising phase reflecting the activation of the phototransduction cascade (Lamb and Pugh, 1992) and their recovery phase reflecting a series of biochemical reactions responsible for cascade inactivation (Burns and Pugh, 2010). Our data reveal 

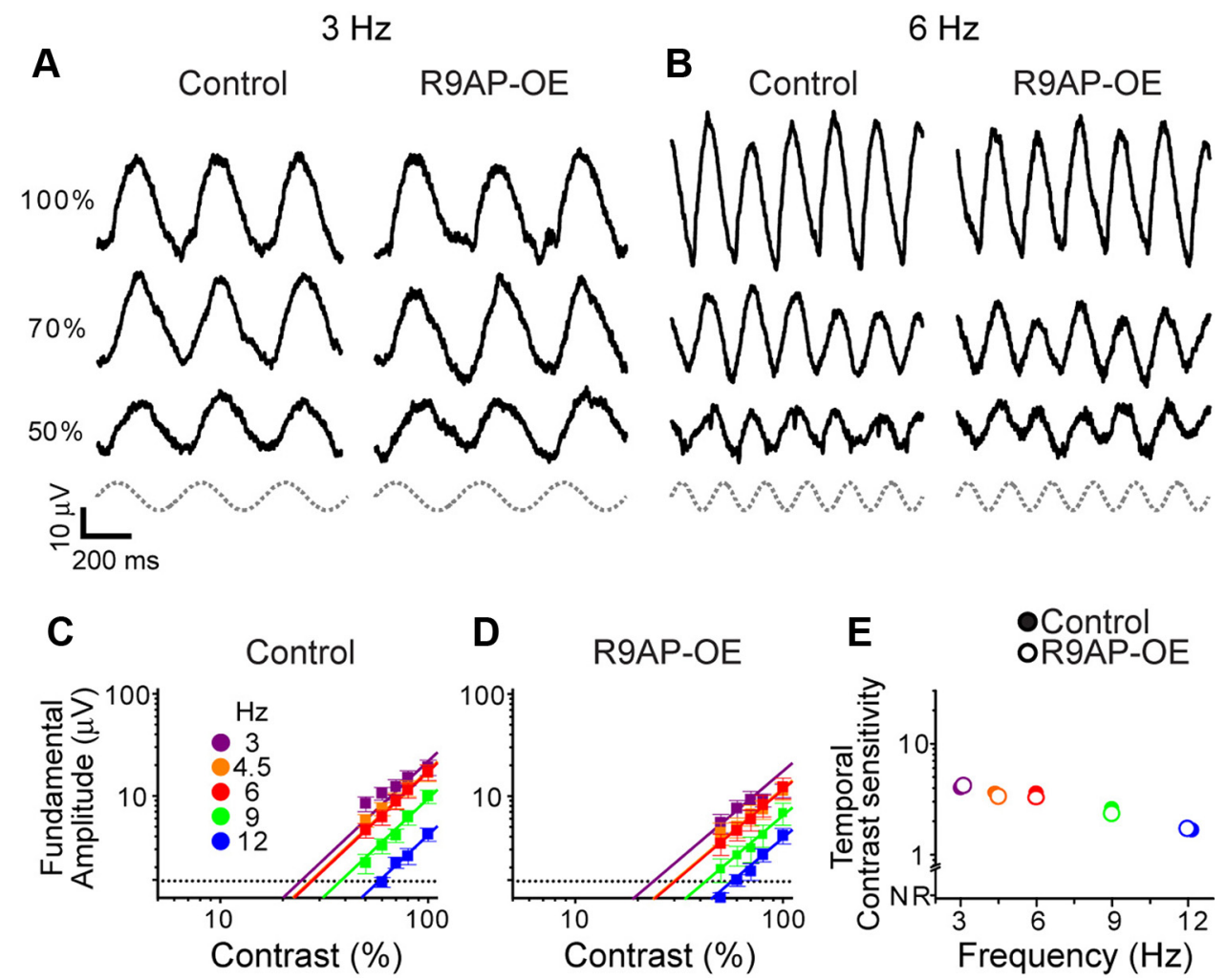

Figure 5. Mice overexpressing R9AP in their rods have normal flicker ERG sensitivity in dim light. $A, B$, Representative flicker ERGs obtained from control and R9AP-0E mice were recorded at $3 \mathrm{~Hz}$ $(\boldsymbol{A})$ or $6 \mathrm{~Hz}(\boldsymbol{B})$ at the illuminance of $1.9 \times 10^{-3}$ Trolands $\left(\sim 0.4 \mathrm{R}^{*} / \mathrm{rod} / \mathrm{s}\right)$. Traces are averages among 30 individual trials in response to sinusoidal, full-field stimuli represented by the gray dotted lines. The values of contrast are shown. $\boldsymbol{C}, \boldsymbol{D}$, Magnitudes of the fundamental flicker ERG component are plotted as functions of stimulus contrast at various flicker frequencies for control ( $\boldsymbol{C}$ ) and R9AP-OE (D) mice. Data points represent mean \pm SEM; $n=4$ for control and 8 for R9AP-0E mice. Data were fitted to Equation 1 (see Materials and Methods). $\boldsymbol{E}$, Temporal contrast sensitivity (the inverse of contrast required to reach the $1.5 \mu \mathrm{V}$ threshold determined from $\boldsymbol{C}$ and $\boldsymbol{D}$ ) as a function of flicker frequency in control (filled symbols) and R9AP-0E (open symbols) mice.

that, in very dim light, when the average time between the absorptions of two successive photons exceeds the time of photoresponse recovery, slow inactivation of $R 9 A P^{-1-}$ rods does not affect contrast sensitivity measured by either technique. This conclusion is reinforced by behavioral experiments with mice overexpressing R9AP in their rods. Although their single-photon responses recover $\sim 2.5$-fold faster than normally (Krispel et al., 2006), no deviation from normal temporal and speed contrast sensitivities was observed in these animals.

Our finding that large changes in photoresponse recovery kinetics do not influence the temporal contrast sensitivity of roddominant vision is very surprising because rods use an array of highly sophisticated molecular machinery, including precise timing of rhodopsin inactivation (Arshavsky, 2002) and $\mathrm{Ca}^{2+}$ dependent feedback of cGMP restoration (Burns and Pugh, 2010), to ensure a high degree of reproducibility of their singlephoton response kinetics. Perhaps this precision in photoresponse inactivation becomes critical only when rods integrate multiple photon events in brighter light. Conversely, our finding is generally consistent with rod ON-bipolar cells and downstream retinal circuitry responding primarily to the early, rising phase of the rod light responses (Schnapf and Copenhagen, 1982; Robson and Frishman, 1995; Sampath et al., 2005). Indeed, the rising phase of single-photon responses remains essentially unchanged in all animal models we used (Keresztes et al., 2004; Krispel et al., 2006). This suggests that response recovery under single-photon counting conditions resets the resting state of light-responding rods but does not determine the temporal characteristics of the downstream responses.
Slow photoresponse recovery reduces temporal contrast sensitivity in moderate and bright light

Our second major result is that slow photoresponse recovery in $R 9 A P^{-1-}$ mice impairs temporal contrast sensitivity under illumination conditions exceeding the single-photon counting regimen. Clearly, this affects both rods and cones because rods remain far from saturating at the light intensity at which the $R 9 A P^{-1-}$ phenotype becomes prominent (Nakatani et al., 1991). Furthermore, contrast sensitivity functions documented by ERG and behavioral assays followed similar trends in $R 9 A P^{-/-}$and $R 9 A P^{+/+}$animals, suggesting that control of behavioral temporal contrast sensitivity may occur primarily in the retina. This observation strengthens the interpretation of electrophysiological and psychophysical tests in humans that the sensitivity to sinusoidally modulated light is controlled primarily at early stages of visual processing in the retina (Kelly, 1972; Purpura et al., 1990; Seiple et al., 1992).

Another interesting observation relates to the abnormal contrast sensitivity tuning in $R 9 A P^{-/-}$mice. As described in Results, the scotopic (rod-dominant) vision of normal mice is tuned to temporal frequency, whereas their photopic (cone-dominant) and mesopic (carried by both rods and cones) vision are tuned to speed (Umino et al., 2008). $R 9 A P^{-1-}$ mice display normal temporal tuning of their rod-dominant vision but fail to completely transition from temporal to speed tuning in bright light. This defect is caused by a loss in sensitivity to temporal frequencies exceeding a critical value of $1.5 \mathrm{~Hz}$ (Fig. $4 B$ ). Such a behavior resembles a classic "low-pass" filter, which allows normal sensitivity at low frequencies but attenuates responses at high frequencies, 


\section{$8 \cdot 10^{-5}$ Trolands}

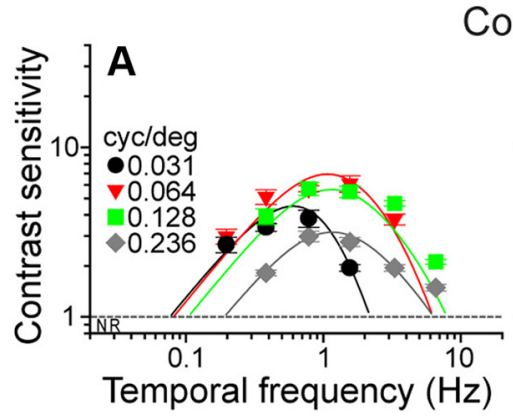

Control
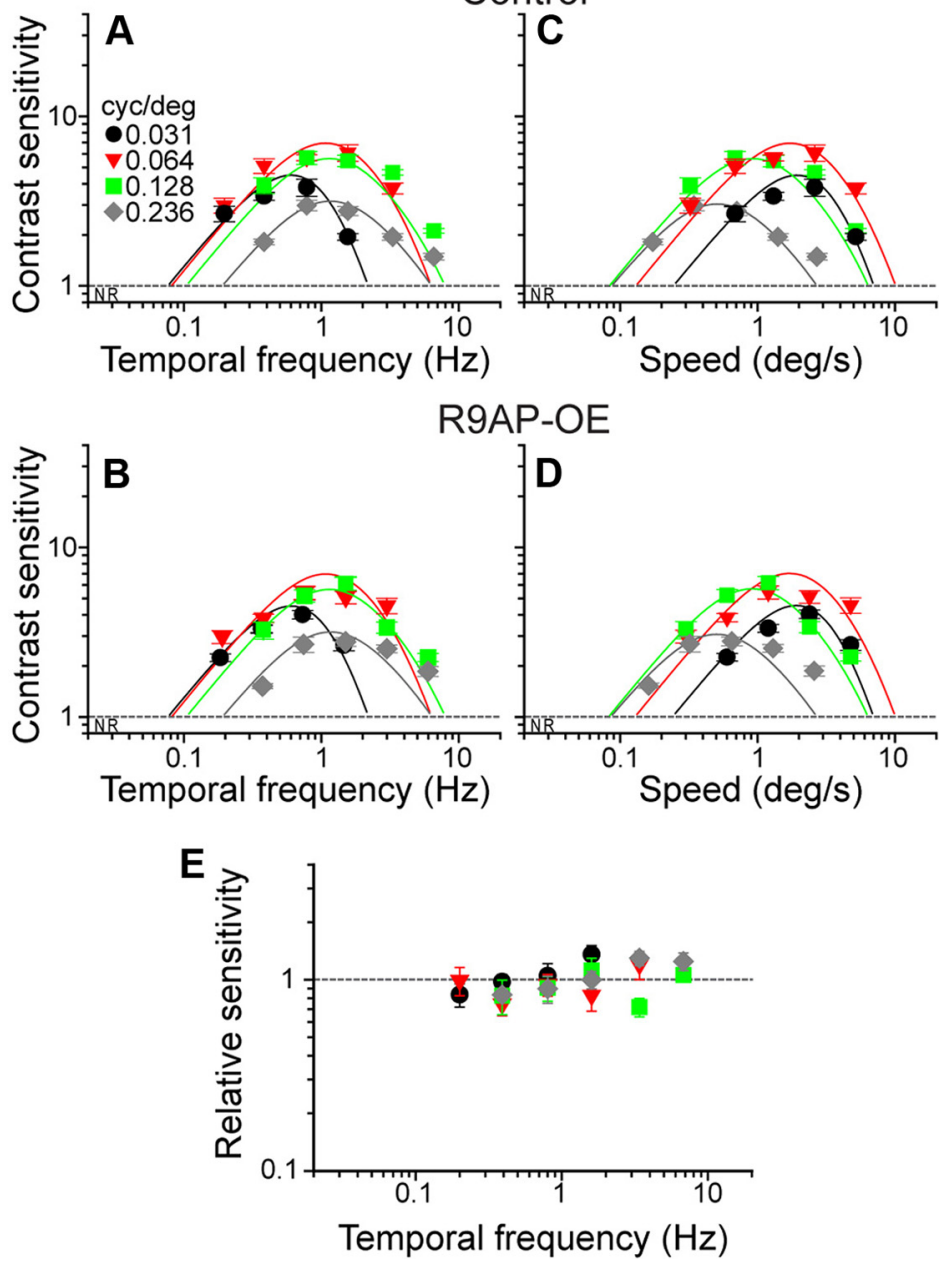

Figure 6. Mice overexpressing R9AP in their rods have normal behavioral dim-light contrast sensitivity. $\boldsymbol{A}-\boldsymbol{D}$, Families of temporal and speed contrast sensitivity functions of R9AP- 0 E and control mice determined at $8 \times 10^{-5}$ Trolands $\left(0.02 \mathrm{R}^{*} / \mathrm{rod} / \mathrm{s}\right)$. Continuous lines represent fits of the data to Equation 2 with fitting parameters listed in Table $1 ; R^{2}>0.8$ in plots $A$ and $C$, and $R^{2}$ $=0.7$ for $B$ and $\boldsymbol{D}$. Data points represent mean \pm SEM; $n=8$ for R9AP-0E mice and 4 for control mice. NR, No optomotor response. $\boldsymbol{E}$, Relative sensitivities, calculated as the ratio between the contrast sensitivities of R9AP-0E mice and their control WT littermates.
(Nishiguchi et al., 2004; Cheng et al., 2007; Hartong et al., 2007; Stockman et al., 2008; Michaelides et al., 2010), characterized by a difficulty to see low-contrast moving objects, adapting to abrupt changes in ambient light intensity, and photophobia, i.e., intolerance to bright light. These conditions are consistent with slow photoresponse recovery from excitation and excessive signaling in bright light. ERG recordings conducted with bradyopsia patients revealed several common trends with mice lacking the RGS9:G $\beta 5$ : R9AP complex, including unaffected b-wave responses to dim flashes, severely delayed response recovery after a bright flash, and nearly abolished flicker ERGs recorded in the photopic range (Nishiguchi et al., 2004; Cheng et al., 2007; Hartong et al., 2007; Michaelides et al., 2010). One of these studies showed an essentially normal flicker ERG recorded from two patients in dim light, yet a nearly flat flicker ERG in bright light (Michaelides et al., 2010). All of these observations are in line with the flicker ERG phenotype of $R 9 A P^{-/-}$mice described in our study.

At present, there is no quantitative data describing the difficulty to see moving objects by the bradyopsia patients. The best documentation reported so far was obtained from a single R9AP knockout subject assessed by the dynamic acuity test (Nishiguchi et al., 2004). The patient's ability to see an object moving at $18.5^{\circ}$ s at a low $10 \%$ contrast was essentially abolished, whereas his ability to see the same object at a $100 \%$ contrast was normal. Because this test was conducted under photopic conditions, its outcome is entirely apparently because of a slow recovery rate of mutant photoreceptors. Consequently, the contrast sensitivity functions that normally peak above the temporal frequency of $1.5 \mathrm{~Hz}$ are affected the most (Fig. 3, compare E, F). Ultimately, all contrast sensitivity functions in $R 9 A P^{-1-}$ mice peak close to a common optimal frequency $\sim 1.5 \mathrm{~Hz}$, which resembles the "temporally" tuned sensitivity functions of rod-dominant vision.

\section{Comparison of visual function in $R 9 A P^{-/-}$mice and bradyopsia patients}

Vision in mice and humans share many cellular and physiological features, including low visual sensitivity threshold (Hecht et al., 1942; Nathan et al., 2006; Naarendorp et al., 2010), bandpassshaped visual contrast sensitivity functions (van Nes et al., 1967; Prusky et al., 2004), classic Weber-like light adaptation (Aguilar and Stiles, 1954; Naarendorp et al., 2010), and light-dependent increase in temporal resolution (Kelly, 1972; Umino et al., 2008). Therefore, it is interesting to compare insights drawn from the present study to visual deficits experienced by human patients with bradyopsia. As mentioned above, bradyopsia is a congenital condition caused by mutations in the RGS9 and R9AP genes

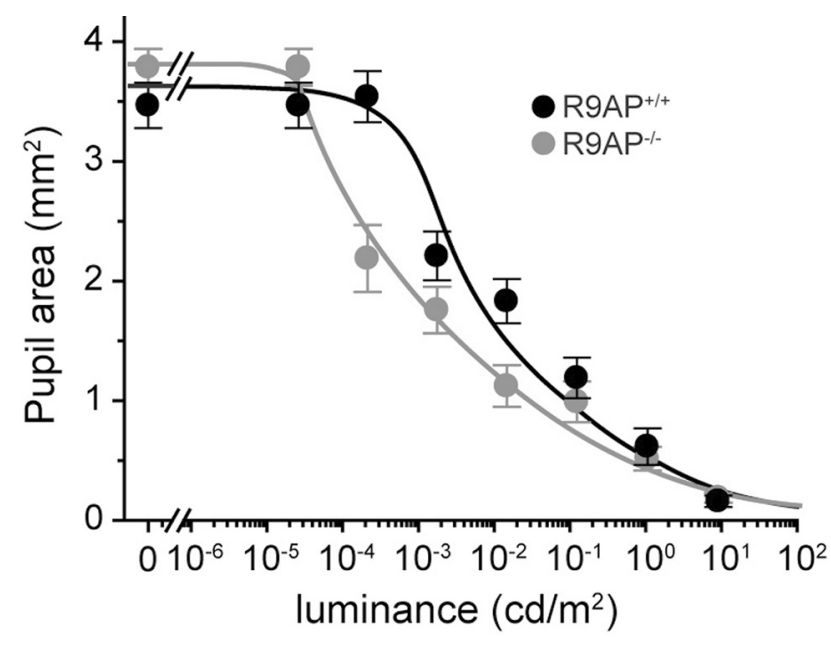

Figure 7. The pupillary light reflex is more sensitive in $R 9 A P^{-/-}$mice than in their $R 9 A P^{+1+}$ littermates. Pupil areas were measured in unrestrained mice and plotted as a function of luminance. Data points (mean $\pm \mathrm{SEM} ; n=6$ and 7 for $R 9 A P^{+/+}$and $R 9 A P^{-/-}$mice, respectively) and connected by a smooth line. 


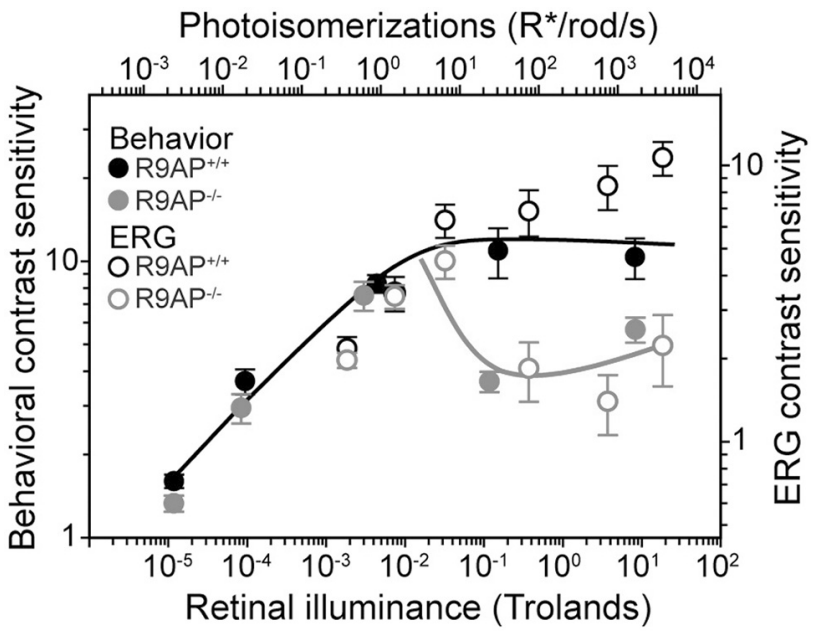

Figure 8. Parallel changes in the contrast sensitivities of flicker ERG and behavioral assay in $R 9 A P^{+/+}$and $R 9 A P^{-/-}$mice. Contrast sensitivities determined by either technique were plotted as functions of background light intensity. The temporal frequency of $3 \mathrm{~Hz}$ was used in both assays; the spatial frequency of 0.128 cycles $/{ }^{\circ}$ was used in the behavioral assay. The ordinate of the ERG plot was scaled to display the best match between the trends of the two plots. The rate of rhodopsin photoisomerization at each light intensity is shown at the abscissa on the top.

consistent with our observations in $R 9 A P^{-/-}$mice. Our results further suggest that the degree of this impairment would increase with speed (or temporal frequency) but may be rescued by increasing the size (i.e., lowering the spatial frequency) of the moving object, a prediction testable in psychophysical studies. It would be also very interesting to analyze whether the dynamic acuity of these patients remains normal under scotopic conditions, as we observed in mice.

\section{References}

Abd-El-Barr MM, Pennesi ME, Saszik SM, Barrow AJ, Lem J, Bramblett DE, Paul DL, Frishman LJ, Wu SM (2009) Genetic dissection of rod and cone pathways in the dark-adapted mouse retina. J Neurophysiol 102:1945-1955.

Aguilar M, Stiles W (1954) Saturation of rod mechanisms of the retina at high levels of illumination. Optica Acta 1:59-65.

Arshavsky VY (2002) Rhodopsin phosphorylation: from terminating single photon responses to photoreceptor dark adaptation. Trends Neurosci 25:124-126.

Arshavsky VY, Lamb TD, Pugh EN Jr (2002) G proteins and phototransduction. Annu Rev Physiol 64:153-187.

Baylor DA, Hodgkin AL (1973) Detection and resolution of visual stimuli by turtle photoreceptors. J Physiol 234:163-198.

Baylor DA, Lamb TD, Yau KW (1979) Responses of retinal rods to single photons. J Physiol 288:613-634.

Blundell J, Hoang CV, Potts B, Gold SJ, Powell CM (2008) Motor coordination deficits in mice lacking RGS9. Brain Res 1190:78-85.

Burns ME, Baylor DA (2001) Activation, deactivation, and adaptation in vertebrate photoreceptor cells. Annu Rev Neurosci 24:779-805.

Burns ME, Pugh EN Jr (2010) Lessons from photoreceptors: turning off g-protein signaling in living cells. Physiology (Bethesda) 25:72-84.

Bush RA, Sieving PA (1996) Inner retinal contributions to the primate photopic fast flicker electroretinogram. J Opt Soc Am A Opt Image Sci Vis 13:557-565.

Cao Y, Masuho I, Okawa H, Xie K, Asami J, Kammermeier PJ, Maddox DM, Furukawa T, Inoue T, Sampath AP, Martemyanov KA (2009) Retinaspecific GTPase accelerator RGS11/G $\beta$ 5S/R9AP is a constitutive heterotrimer selectively targeted to mGluR6 in ON-bipolar neurons. J Neurosci 29:9301-9313.

Chen CK, Burns ME, He W, Wensel TG, Baylor DA, Simon MI (2000) Slowed recovery of rod photoresponse in mice lacking the GTPase accelerating protein RGS9-1. Nature 403:557-560.
Chen CK, Eversole-Cire P, Zhang H, Mancino V, Chen YJ, He W, Wensel TG, Simon MI (2003) Instability of GGL domain-containing RGS proteins in mice lacking the $G$ protein beta-subunit Gbeta5. Proc Natl Acad Sci U S A 100:6604-6609.

Chen FS, Shim H, Morhardt D, Dallman R, Krahn E, McWhinney L, Rao A, Gold SJ, Chen CK (2010) Functional redundancy of R7 RGS proteins in ON-bipolar cell dendrites. Invest Ophthalmol Vis Sci 51:686-693.

Cheng JY, Luu CD, Yong VH, Mathur R, Aung T, Vithana EN (2007) Bradyopsia in an Asian man. Arch Ophthalmol 125:1138-1140.

Douglas RM, Alam NM, Silver BD, McGill TJ, Tschetter WW, Prusky GT (2005) Independent visual threshold measurements in the two eyes of freely moving rats and mice using a virtual-reality optokinetic system. Vis Neurosci 22:677-684.

Dryja TP (2000) Molecular genetics of Oguchi disease, fundus albipunctatus, and other forms of stationary night blindness: LVII Edward Jackson Memorial Lecture. Am J Ophthalmol 130:547-563.

Fain GL, Matthews HR, Cornwall MC, Koutalos Y (2001) Adaptation in vertebrate photoreceptors. Physiol Rev 81:117-151.

Fu Y, Yau KW (2007) Phototransduction in mouse rods and cones. Pflugers Arch 454:805-819.

Hartong DT, Pott JW, Kooijman AC (2007) Six patients with bradyopsia (slow vision): clinical features and course of the disease. Ophthalmology 114:2323-2331.

He W, Cowan CW, Wensel TG (1998) RGS9, a GTPase accelerator for phototransduction. Neuron 20:95-102.

Hecht S, Shlaer S, Pirenne MH (1942) Energy, quanta, and vision. J Gen Physiol 25:819-840.

Herrmann R, Lobanova ES, Hammond T, Kessler C, Burns ME, Frishman LJ, Arshavsky VY (2010) Phosducin regulates transmission at the photoreceptor-to-ON-bipolar cell synapse. J Neurosci 30:3239-3253.

Herrmann R, Lee B, Arshavsky VY (2011) RGS9 knockout causes a short delay in light responses of ON-bipolar cells. PLoS One 6:e27573.

Hu G, Wensel TG (2002) R9AP, a membrane anchor for the photoreceptor GTPase accelerating protein, RGS9-1. Proc Natl Acad Sci U S A 99:9755-9760.

Jeffrey BG, Morgans CW, Puthussery T, Wensel TG, Burke NS, Brown RL, Duvoisin RM (2010) R9AP stabilizes RGS11-G beta5 and accelerates the early light response of ON-bipolar cells. Vis Neurosci 27:9-17.

Kelly DH (1972) Adaptation effects on spatio-temporal sine-wave thresholds. Vision Res 12:89-101.

Keresztes G, Martemyanov KA, Krispel CM, Mutai H, Yoo PJ, Maison SF, Burns ME, Arshavsky VY, Heller S (2004) Absence of the RGS9.Gbeta5 GTPase-activating complex in photoreceptors of the R9AP knockout mouse. J Biol Chem 279:1581-1584.

Krishna VR, Alexander KR, Peachey NS (2002) Temporal properties of the mouse cone electroretinogram. J Neurophysiol 87:42-48.

Krispel CM, Chen D, Melling N, Chen YJ, Martemyanov KA, Quillinan N, Arshavsky VY, Wensel TG, Chen CK, Burns ME (2006) RGS expression rate-limits recovery of rod photoresponses. Neuron 51:409-416.

Lamb TD, Pugh EN Jr (1992) A quantitative account of the activation steps involved in phototransduction in amphibian photoreceptors. J Physiol 449:719-758.

Lobanova ES, Finkelstein S, Song H, Tsang SH, Chen CK, Sokolov M, Skiba NP, Arshavsky VY (2007) Transducin translocation in rods is triggered by saturation of the GTPase-activating complex. J Neurosci 27:1151-1160.

Lyubarsky AL, Naarendorp F, Zhang X, Wensel T, Simon MI, Pugh EN Jr (2001) RGS9-1 is required for normal inactivation of mouse cone phototransduction. Mol Vis 7:71-78.

Lyubarsky AL, Daniele LL, Pugh EN Jr (2004) From candelas to photoisomerizations in the mouse eye by rhodopsin bleaching in situ and the light-rearing dependence of the major components of the mouse ERG. Vision Res 44:3235-3251

Makino ER, Handy JW, Li T, Arshavsky VY (1999) The GTPase activating factor for transducin in rod photoreceptors is the complex between RGS9 and type $5 \mathrm{G}$ protein beta subunit. Proc Natl Acad Sci USA 96:1947-1952.

Michaelides M, Li Z, Rana NA, Richardson EC, Hykin PG, Moore AT, Holder GE, Webster AR (2010) Novel mutations and electrophysiologic findings in RGS9- and R9AP-associated retinal dysfunction (Bradyopsia). Ophthalmology 117:120.el-127.e1.

Mojumder DK, Qian Y, Wensel TG (2009) Two R7 regulator of G-protein 
signaling proteins shape retinal bipolar cell signaling. J Neurosci 29:7753-7765.

Morgans CW, Wensel TG, Brown RL, Perez-Leon JA, Bearnot B, Duvoisin RM (2007) Gbeta5-RGS complexes co-localize with mGluR6 in retinal ON-bipolar cells. Eur J Neurosci 26:2899-2905.

Naarendorp F, Esdaille TM, Banden SM, Andrews-Labenski J, Gross OP, Pugh EN Jr (2010) Dark light, rod saturation, and the absolute and incremental sensitivity of mouse cone vision. J Neurosci 30:12495-12507.

Nakatani K, Tamura T, Yau KW (1991) Light adaptation in retinal rods of the rabbit and two other nonprimate mammals. J Gen Physiol 97:413-435.

Nathan J, Reh R, Ankoudinova I, Ankoudinova G, Chang B, Heckenlively J, Hurley JB (2006) Scotopic and photopic visual thresholds and spatial and temporal discrimination evaluated by behavior of mice in a water maze. Photochem Photobiol 82:1489-1494.

Nishiguchi KM, Sandberg MA, Kooijman AC, Martemyanov KA, Pott JW, Hagstrom SA, Arshavsky VY, Berson EL, Dryja TP (2004) Defects in RGS9 or its anchor protein R9AP in patients with slow photoreceptor deactivation. Nature 427:75-78.

Pasternak T, Merigan WH (1981) The luminance dependence of spatial vision in the cat. Vision Res 21:1333-1339.

Prusky GT, Alam NM, Beekman S, Douglas RM (2004) Rapid quantification of adult and developing mouse spatial vision using a virtual optomotor system. Invest Ophthalmol Vis Sci 45:4611-4616.

Purpura K, Tranchina D, Kaplan E, Shapley RM (1990) Light adaptation in the primate retina: analysis of changes in gain and dynamics of monkey retinal ganglion cells. Vis Neurosci 4:75-93.

Rahman Z, Schwarz J, Gold SJ, Zachariou V, Wein MN, Choi KH, Kovoor A, Chen CK, DiLeone RJ, Schwarz SC, Selley DE, Sim-Selley LJ, Barrot M, Luedtke RR, Self D, Neve RL, Lester HA, Simon MI, Nestler EJ (2003) RGS9 modulates dopamine signaling in the basal ganglia. Neuron 38:941-952.

Rao A, Dallman R, Henderson S, Chen CK (2007) Gbeta5 is required for normal light responses and morphology of retinal ON-bipolar cells. J Neurosci 27:14199-14204.

Rieke F, Baylor DA (1998) Origin of reproducibility in the responses of retinal rods to single photons. Biophys J 75:1836-1857.

Robson JG, Frishman LJ (1995) Response linearity and kinetics of the cat retina: the bipolar cell component of the dark-adapted electroretinogram. Vis Neurosci 12:837-850.
Sampath AP, Strissel KJ, Elias R, Arshavsky VY, McGinnis JF, Chen J, Kawamura S, Rieke F, Hurley JB (2005) Recoverin improves rod-mediated vision by enhancing signal transmission in the mouse retina. Neuron 46:413-420.

Saszik SM, Robson JG, Frishman LJ (2002) The scotopic threshold response of the dark-adapted electroretinogram of the mouse. J Physiol 543:899-916.

Schnapf JL, Copenhagen DR (1982) Differences in the kinetics of rod and cone synaptic transmission. Nature 296:862-864.

Seiple W, Holopigian K, Greenstein V, Hood DC (1992) Temporal frequency dependent adaptation at the level of the outer retina in humans. Vision Res 32:2043-2048.

Shapley R, Enroth-Cugell C (1984) Visual adaptation and retinal gain controls. Prog Retin Res 3:263-346.

Shirato S, Maeda H, Miura G, Frishman LJ (2008) Postreceptoral contributions to the light-adapted ERG of mice lacking b-waves. Exp Eye Res 86:914-928.

Sokolov M, Lyubarsky AL, Strissel KJ, Savchenko AB, Govardovskii VI, Pugh EN Jr, Arshavsky VY (2002) Massive light-driven translocation of transducin between the two major compartments of rod cells: a novel mechanism of light adaptation. Neuron 34:95-106.

Stockman A, Langendörfer M, Smithson HE, Sharpe LT (2006) Human cone light adaptation: from behavioral measurements to molecular mechanisms. J Vis 6:1194-1213.

Stockman A, Smithson HE, Webster AR, Holder GE, Rana NA, Ripamonti C, Sharpe LT (2008) The loss of the PDE6 deactivating enzyme, RGS9, results in precocious light adaptation at low light levels. J Vis 8:10 11-10.

Umino Y, Solessio E, Barlow RB (2008) Speed, spatial, and temporal tuning of rod and cone vision in mouse. J Neurosci 28:189-198.

van Nes FL, Koenderink JJ, Nas H, Bouman MA (1967) Spatiotemporal modulation transfer in the human eye. J Opt Soc Am 57:1082-1088.

West SK, Rubin GS, Broman AT, Muñoz B, Bandeen-Roche K, Turano K (2002) How does visual impairment affect performance on tasks of everyday life? The SEE Project. Salisbury Eye Evaluation. Arch Ophthalmol 120:774-780

Whitlock GG, Lamb TD (1999) Variability in the time course of single photon responses from toad rods: termination of rhodopsin's activity. Neuron 23:337-351.

Wu S, Burns SA (1996) Analysis of retinal light adaptation with the flicker electroretinogram. J Opt Soc Am A Opt Image Sci Vis 13:649-657. 